\title{
Sobre corpos isolados na imagem: a mise en scène em Sangue negro, de Paul Thomas Anderson
}

\section{Thiago da Silva Rabelo}

Mestrando; Universidade Federal de Goiás, Goiânia, GO, Brasil thirabeloo@gmail.com

\section{Rosana Maria Ribeiro Borges}

Pós-Doutora; Universidade Federal de Goiás, Goiânia, GO, Brasil rosanaborges.ufg@gmail.com

\section{Resumo}

$\mathrm{O}$ artigo possui como temática o estilo no cinema independente norte-americano. $\mathrm{O}$ objetivo é investigar elementos de mise en scène presentes no filme Sangue negro (2007), dirigido por Paul Thomas Anderson, associando-os às funções do estilo cinematográfico descritas por Bordwell (2008). De abordagem qualitativa e utilizando como método a análise fílmica, a pesquisa foi delineada com base em três momentos do longametragem, escolhidos a partir do interesse em estudar como Anderson conduz o posicionamento e o movimento dos atores dentro do quadro. Como resultado, observou-se que o cineasta, a partir de um constante interesse pelos aspectos mínimos da imagem bidimensional, aposta num recorrente jogo de velar e desvelar em que não apenas corpos e rostos são ocultados e assumidos, mas também representações subjetivas importantes para uma compreensão ampla da narrativa.

\section{Palavras-chave}

Cinema. Mise en scène. Sangue negro. Estilo. Paul Thomas Anderson.

\section{Introdução}

"Você está destruindo a imagem que tenho de você como meu filho" (SANGUE..., 2007, doc. não paginado). É assim que Daniel Plainview (Daniel Day-Lewis) define o estágio em que sua relação com H. W. (Russell Harvard) se encontra nos momentos finais de Sangue negro (2007), longa-metragem dirigido por Paul Thomas Anderson. No filme, acompanhamos o personagem durante três décadas, período no qual Plainview ergue um 
império no mercado de combustíveis fósseis. Prospector e extrator de petróleo, o sujeito nutre profundo desprezo por relações interpessoais, encontrando alguma forma de conexão apenas na figura de seu filho adotivo. No entanto, um acidente ocorrido em uma plataforma de extração faz com que H. W. fique surdo, obrigando Plainview a se isolar cada vez mais e, com isso, caminhar pouco a pouco em direção à loucura.

A ideia de destruição de uma imagem, além de ser sensível a uma investigação atraída pelo fazer cinematográfico, remete à própria degradação pessoal e social de Plainview, reverberando inquietações relacionadas à maneira através da qual Paul Thomas Anderson concebe seu trabalho formalmente. Em suma, o que procuramos entender é como a mise en scène em Sangue negro (2007) traduz em imagens a espiral de conflitos presente no filme, sejam eles externos ou internos. Tomando como referência o que o diretor estadunidense mostra em termos narrativos - fragmentos da vida de um sujeito repleto de fissuras emocionais e, por isso, incapaz de se relacionar com outras pessoas -, interessa-nos entender como ele elabora esteticamente os desdobramentos desta condição, comunicando durante o processo ideias específicas e, principalmente, dinâmicas afetivas que pontuem a trajetória de Plainview. A proposta, portanto, diz respeito a uma investigação estilística ancorada no filme.

No cinema, a noção de estilo se relaciona diretamente com o trabalho dos diretores. Para Bordwell, Thompson e Smith (2017), são eles os responsáveis não apenas por conduzir equipe técnica e elenco, mas também por dirigir a atenção do espectador. Para isso, utilizam-se de decisões técnicas responsáveis por definir o que vemos, o que ouvimos e como deveríamos responder a determinada obra. Como essas decisões são executadas é o que nos interessa.

Levando isso em consideração, o artigo tem em seus primeiros tópicos um breve resgate da obra de Paul Thomas Anderson e de sua relação com o cinema independente dos Estados Unidos, além de tratar sobre conceitos fundamentais dos estudos estilísticos no cinema. Sabemos por Thompson (1988) que é necessário um enfoque ao realizarmos uma análise fílmica. Por isso, o texto traz em sua metade final um estudo sobre como Anderson utiliza a posição e a movimentação dos atores dentro do quadro. Nesse sentido, segmentamos o recurso em três vertentes: na primeira, tratamos dos corpos que, em Sangue negro (2007), conduzem a atenção; na segunda, dos corpos que estabelecem relações de poder ao longo do filme; por fim, voltamos nossa atenção aos corpos que comunicam afetos, vertente que, numa hipótese preliminar, parece ser o principal elemento estilístico da obra.

Cabe ressaltar que consideramos como base teórica de coleta e análise as quatro definições que Bordwell (2008) aponta ao tratar sobre as funções do estilo cinematográfico 
- separando-as em denotativa, expressiva, simbólica e decorativa. É a partir delas que procuramos obter de Sangue negro (2007) os dados iniciais que, em estudos posteriores, serão relacionados a outros elementos de encenação e também a outros filmes do diretor.

\section{0 cinema de Paul Thomas Anderson}

Nascido em território norte-americano no ano de 1970, Paul Thomas Anderson possui uma carreira ainda recente - seu primeiro longa-metragem data do ano de 1996 -, mas que muitos já consideram como marcante na história do cinema. Segundo o Internet Movie Database (IMDB, [2018a]) ${ }^{1}$, o cineasta tem no currículo 39 créditos de direção, dentre os quais estão alguns curtas-metragens e diversos videoclipes. No cinema, e mais especificamente trabalhando com longas, Anderson conta com 9 títulos. Alguns deles, como Boogie nights: prazer sem limites, lançado em 1997, Magnólia, de 1999, e o próprio Sangue negro (2007), foco do presente estudo, alçaram o nome de Anderson ao estrelato, culminando em indicações a grandes prêmios do cinema².

Muitos acreditam que parte do sucesso que o diretor conseguiu alcançar se justifica por um suposto estranhamento inerente às suas obras. Tal estranhamento, segundo Toles (2016), nasce de um interesse constante do cineasta por personagens que, de uma forma ou de outra, encontram-se desconectados do mundo. De certa maneira, tratam-se de escolhas narrativas que remetem à própria trajetória do cinema independente dos Estados Unidos, contexto do qual Anderson emergiu enquanto realizador de destaque. Segundo King (2005), não é raro que filmes considerados independentes adotem como uma de suas estratégias “[...] romper ou abandonar as fluidas convenções associadas ao estilo mainstream de Hollywood [...]" (KING, 2005, p. 2, tradução nossa, grifo nosso) ${ }^{3}$.

Possíveis exemplos dessa ruptura ou abandono surgem numa rápida revisão: em Jogada de risco, lançado em 1996, John (John C. Reilly) precisa desesperadamente de dinheiro para enterrar a própria mãe. Em Boogie nights: prazer sem limites, um jovem aspirante à indústria pornô faz de sua equipe de filmagens a família que nunca teve em casa. Já Embriagado de amor, lançado em 2002, traz Barry Egan (Adam Sandler), sujeito violento e oprimido por suas sete irmãs, obcecado por um amor que acaba de chegar à sua vida. No que diz respeito a Magnólia, um mosaico de personagens desprezíveis, carentes e iludidos fazem

\footnotetext{
1 Lista disponível em IMDb ([2018]).

2 Além de ter sido indicado ao Oscar em cinco oportunidades, o diretor já venceu o Festival de Berlim duas vezes, em 2000 e em 2008. Lista de prêmios disponível em IMDb ([2018b]).

${ }^{3}$ No original: they adopt formal strategies that disrupt or abandon the smoothly flowing conventions associated with the mainstream Hollywood style.
} 
do filme algo de sinfônico, chocando-se uns com os outros na busca por algum sentido que justifique todo o sofrimento que enfrentam.

Surge deste padrão narrativo uma provocação relacionada à maneira com que críticos e demais públicos encaram sua obra. Tendo em vista que seus roteiros tendem a ter como principal referência dramática sujeitos que vivem complexas crises afetivas, há quem diga que o diferencial de Anderson como realizador seria uma incomum capacidade de se reinventar formalmente de um filme para o outro ${ }^{4}$. Outros veem no interesse recorrente por simbolismos e alegorias (os versículos bíblicos em Magnólia; o mosaico de cores em Embriagado de Amor) a principal marca do diretor ${ }^{5}$. Em ambos os casos, e em outros prismas propostos desde a década de 90, o que breves reflexões sobre os filmes de Anderson tendem a esboçar é uma investigação sobre seu estilo. Sendo assim, o que propomos para o artigo é um ir-além deste esboço: desejamos nos debruçar sobre uma das obras de Anderson e, amparados pelos estudos da mise em scène no cinema, compreender como o diretor constrói sua encenação.

\section{Mise en scène no cinema}

Falar em estudos formais no cinema remete a um viés de pesquisa no campo das artes conhecido como estilística. Para Wölfflin (2012), “Explicar um estilo é integrá-lo na história geral da época, segundo seu modo de expressão [...]" (WÖLFFLIN, 2012, p. 93, grifo do autor). Notamos aí não apenas a pertinência de se utilizar referências de época quando a intenção é pensar o estilo, mas também o papel central exercido pela individualidade de um(a) artista neste tipo de pesquisa, reforçado pelo uso de termos como expressão. Em outras palavras, falamos sobre o elo mantido entre situações históricas, tecnologia disponível, ideologias predominantes, outros trabalhos artísticos e, evidentemente, decisões individuais dos próprios realizadores. Dessa forma, o conteúdo de uma época é o combustível que alimenta uma determinada imaginação, que a faz sobrepujar condições arbitrárias impostas por amarras sociais e políticas, tornando-se soberana enquanto força criativa. Filmes, enfim, "[...] reagem às forças da cultura muito mais do que às forças da natureza." (THOMPSON, 1988, p. 35).

Dentro dos estudos estilíticos, aqueles voltados à mise en scène há algum tempo ganham destaque. Iniciar uma reflexão sobre o conceito, no entanto, exige que retornemos brevemente ao teatro popular do século XIX. Trata-se, afinal, de um termo nascido nos palcos do período como forma de indicar a função de profissionais responsáveis por

\footnotetext{
4 Exemplo disponível em Tafoya (2014).

5 Exemplo disponível em Caro (2000).
} 
transpor a dramaturgia vista no script para as ações executadas pelos atores. Aumont (2006) aponta que "[...] a cena foi para o teatro aquilo que o quadro foi para a pintura: o artefacto que permite criar, isolar, designar um espaço específico, que escapa às leis do espaço quotidiano [...]" (AUMONT, 2006, p. 12). É justamente a ideia de criação num espaço que ressalta a função do metteur en scène, ou seja, daquele que coloca em cena, definição muito comum também no início do cinema. A contínua e crescente importância dos encenadores ao longo da história, sobretudo pela ascenção do melodrama como alternativa à tragédia clássica, é um dos motivos que justifica a permanência do termo ao longo dos séculos, influenciando diversas formas artísticas e, também, o pensamento crítico a respeito delas.

Colocada em prática no cinema, ainda no início do século $\mathrm{XX}$, a mise en scène (que trataremos ao longo do texto também como encenação) pode ser encarada, portanto, como o ato de "levar alguma coisa para a cena, a fim de mostrá-la" (OLIVEIRA JÚNIOR, 2013, p. 25). No entanto, o conceito, como mostram estudos estilísticos que ganharam força desde a década de 50, vai além disso, gerando controvérsias que dificultam uma posição mais rígida sobre suas principais características. Ainda assim, chama atenção os atritos que ele estimulou numa época em que a montagem era tida como o elemento definidor do cinema.

À medida que o jornalismo cinematográfico progredia nos anos $1910 \mathrm{e}$ 1920, boa parte da crítica tentava provar que o cinema era uma arte distinta que nada ficava devendo ao teatro. 0 que aparecia como 'puramente cinematográfico' era a técnica emergente da montagem, ao passo que a encenação, pelo próprio nome, parecia 'teatral'. [...] Não é de admirar que os críticos mais perspicazes, assim como os teóricos mais imaginativos, com frequência, pregavam as virtudes da montagem e ignoravam a mise-en-scène. Foi preciso uma nova geração de críticos, que cresceu com o cinema sonoro, para equilibrar a balança. (BORDWELL, 2008, p. 29).

Consideramos que as discordâncias entre adeptos da montagem e aqueles que apoiavam a encenação são menos relevantes para uma reflexão sobre a mise en scène. 0 que nos interessa é sua evidente contribuição para o desenvolvimento dos filmes. Neste contexto, o nome de André Bazin surge fundamental para compreendermos o apelo dos estudos sobre encenação no cinema. Crítico e teórico francês, além de um dos fundadores dos Cahiers du Cinèma ${ }^{6}$, são dele alguns dos textos que chamaram atenção para a influência exercida pelas técnicas de direção que, pouco depois, seriam vinculadas ao conceito de mise en scène. Tal influência se manifestava não apenas sobre a reflexão de seus colegas, mas

${ }^{6}$ Publicação francesa voltada à crítica cinematográfica e nascida em meados dos anos 1950 . 
sobre o próprio processo do fazer cinematográfico. A respeito de sua contribuição, entendemos que

Uma variada gama de conceitos analíticos foi proposta por Bazin em seus escritos dos anos 1940 e 1950, mais notadamente sobre certas técnicas que os primeiros estetas negligenciaram: o plano-sequência, o movimento de câmera e a composição em profundidade de campo (profondeur de champ). Os diretores com foco na realidade tendem a recorrer a essas técnicas, mais do que às trucagens da montagem e aos closes, já que querem captar a continuidade espaço-temporal do mundo em que vivemos. Em pouco tempo, entretanto, Bazin viu suas técnicas preferidas serem encampadas por uma geração um pouco mais jovem de críticos apaixonados por Hollywood. (BORDWELL, 2008, p. 32-33)

Os escritores que faziam parte da equipe dos Cahiers du Cinèma ${ }^{7}$ na época em que Bazin comandava a revista, conhecidos como jovens turcos, se recusaram a adotar totalmente o discurso de seu líder, pautado, entre outros fatores, por uma concepção favorável a uma suposta capacidade que o cinema teria de apreender a realidade fenomênica do mundo. Para eles, a busca por um suposto realismo fotográfico, tão cara a Bazin, seria algo menor quando comparada aos artifícios expressivos que os cineastas utilizam para apresentar uma "visão particular de mundo" (BORDWELL, 2008, p. 33). Com isso, surge aquela que ficou conhecida como a "política dos autores", defendida por vários integrantes da publicação e que pode ser entendida com mais profundidade em escritos como o de Baecque (2010).

Convém apontar, no entanto, que a iniciativa dos Cahiers... diz respeito menos a uma teoria bem fundamentada do que a uma forma muito particular de encarar o cinema, de produzir um manifesto repleto de paixão sobre ele. Mesmo assim, e apesar de um relativo deslumbramento discursivo com a forma fílmica, justificado tanto pelas raízes bazinianas da equipe quanto pela vontade que tinham de questionar a produção francesa em voga na época, os jovens turcos podem ser encarados como responsáveis por um dos marcos dos estudos fílmicos. Isso se dá justamente pela atenção que eles direcionaram às escolhas específicas dos cineastas durante o processo de feitura de uma obra. É esse o ponto que procuramos utilizar como fio condutor da pesquisa.

No que diz respeito aos estudos contemporâneos sobre encenação no cinema, o interesse por essas escolhas ganhou espaço considerável e, hoje, faz parte de qualquer abordagem estilística proveniente de investigações acadêmicas no cinema. Para definir mise en scène, por exemplo, é comum que pesquisadores se voltem à tradição dos críticos

\footnotetext{
${ }^{7}$ François Truffaut, Jean-Luc Godard, Jacques Rivette, Éric Rohmer, Claude Chabrol, entre outros.
} 
franceses, ao trabalho pioneiro do teórico e cineasta soviético Sergei Eisenstein - inspirado, por sua vez, pelo teatro de Vsevolod Meyerhold - e ao que diziam os autores da Présence du Cinéma, outra revista francesa voltada a estudos do tipo e que manteve-se ativa de 1959 a 1967. Tratam-se de visões mais ou menos distintas que foram trabalhadas de modo a criar uma síntese de elementos comuns e complementares que pudessem ser utilizados durante as análises dos teóricos em questão. Nesse sentido, Bordwell (2008) apresenta uma definição que consideramos capaz de reunir as principais características de todas essas visões, e que, por isso, atua como parte do marco teórico a ser seguido ao longo do presente estudo. Segundo o autor,

[...] o essencial sentido técnico do termo denota cenário, iluminação, figurino, maquiagem e atuação dos atores dentro do quadro. Alguns críticos incluiriam o movimento de câmera como um elemento da mise-enscène, mas prefiro deixá-lo como uma variável independente. A movimentação da câmera diz respeito à cinematografia, não constituindo uma característica do que é filmado. (BORDWELL, 2008, p. 36)

Notamos aí a presença da atuação dos atores dentro do quadro, justamente o elemento da mise en scène que nos interessa em Sangue negro (2007). Dessa forma, retornamos a Bordwell (2008) para resgatar aquilo que o autor considera como as quatro funções do estilo cinematográfico. São elas: a função denotativa, a função expressiva, a função simbólica e a função decorativa. No primeiro caso, trata-se da "descrição de cenários e personagens", da "narração de suas motivações" e da "apresentação dos diálogos e do movimento" (BORDWELL, 2008, p. 59). Em outras palavras, a função denotativa diz respeito àquilo que vemos (movimentos, formas, luzes, sombras, objetos) e ouvimos (ruídos, notas musicais, monólogos, diálogos) tendo como referência o quadro cinematográfico.

Já a função expressiva diz respeito ao uso da cor, da luz, do movimento dos atores, da interpretação (por parte do público) e de outros elementos técnicos como forma de apresentar "qualidades de sentimento" (BORDWELL, 2008, p. 60). Trata-se de uma capacidade que a mise en scène possui de transmitir (ou seja, comunicar) amor, ódio, tristeza e outras vertentes afetivas. Indo além em sua definição, ele aponta que há uma outra possibilidade para o estilo no que diz respeito à sua função expressiva: a de causar sentimentos em quem assiste. A diferença fundamental entre um estilo que comunica e um estilo que causa sentimentos é que, no primeiro, trata-se de uma intenção que nasce da ação do(a) cineasta, do planejamento da forma fílmica executado por ele(a). Já o segundo diz 
respeito, sobretudo, à bagagem subjetiva que espectadores carregam consigo, responsável por fazer um momento ou outro soar de maneira distinta de pessoa para pessoa.

Partindo para a função simbólica, sabemos que "o estilo também pode produzir significados mais abstratos e conceituais" (BORDWELL, 2008, p. 60). Aí está, de acordo com o autor, a função mais utilizada em pesquisas voltadas a cinema ao longo de sua história, com variações transitando através, por exemplo, da Psicanálise, do Marxismo, do Feminismo e dos Estudos Culturais. 0 que importa aqui é uma produção de sentido que transponha os limites denotativos, expressivos e decorativos (sobre os quais falaremos mais adiante) da imagem, alcançando, com isso, reflexões que partem do filme e seguem em direção a inquietações mais amplas sobre a vida e o mundo.

Por fim, a função decorativa aponta para o uso de padrões e variações formais capazes de estabelecer algum tipo de assinatura autoral à cineasta, não possuindo, necessariamente, alguma relevância narrativa. Em suma, é quando o estilo pode "operar por si mesmo" (BORDWELL, 2008, p. 60).

Após analisar as quatro funções do estilo cinematográfico, cabe perguntar: de que forma somos apresentados a cada uma delas? Como devemos nos preparar para reconhecêlas durante uma análise? Segundo o próprio Bordwell (2013), é preciso, acima de tudo, considerar que elas podem atuar tanto isolada quanto simultaneamente num filme, e que só uma análise baseada num enfoque pré-determinado dá conta de decompô-las e segmentá-las com solidez.

\section{Análise fílmica neoformalista}

Para Thompson (1988), são duas as maneiras de conduzirmos uma análise fílmica. Na primeira delas, temos o enfoque numa abordagem pré-determinada. Na segunda, uma análise interessada pelo filme em si. No geral, a escolha por uma ou por outra depende dos motivos pelos quais uma analista deseja estudar determinada obra. A respeito da primeira, trata-se de uma análise feita a partir de métodos estabelecidos de antemão, e geralmente ligados a áreas com as quais o cinema não se relaciona diretamente. Exemplo disso são os estudos psicanalíticos de filmes, a partir dos quais as conhecidas teorias de Sigmund Freud sobre o inconsciente humano, por exemplo, são usadas à exaustão como forma de pensar o cinema. Em suma, a ideia é apostar num método que existe antes da escolha do próprio objeto, e até mesmo antes do início de qualquer etapa do processo de estudo.

Ao partimos para o filme em si, caso da segunda opção, percebemos pelo próprio termo que a abordagem parte das características intrínsecas da(s) obras(s) escolhida(s), e 
não de teorias pré-estabelecidas por algum campo de estudo distinto. Falamos, portanto, do neoformalismo, que, importante dizer, não pode ser encarado como um método propriamente dito, mas como uma “[...] série de considerações básicas que podem ser organizadas de modo a construir um método específico para resolver os problemas levantados por cada filme." (THOMPSON, 1988, p. 6, tradução nossa) ${ }^{8}$. Das considerações citadas por Thompson (1988), interessam para o estudo proposto a ideia de desfamiliarização ${ }^{9}$, esquemas e motifs. É a partir delas que pensaremos as quatro funções do estilo cinematográfico em Sangue negro (2007), adotando como recorte a maneira com que os personagens se deslocam dentro do quadro.

Foram formalistas russos como Shklovsky (1991) que apontaram a técnica artística como tendo a função de trazer algum nível de desfamiliarização ao nosso dia a dia. Para eles, percepções práticas são aquelas que utilizamos nos afazeres cotidianos, ao passo que uma percepção não-prática seria própria de uma obra de arte, por exemplo, com base na qual participamos de uma experiência estética que, de alguma maneira, quebra a rotina na qual frequentemente estamos inseridos. Assim, dificultar o reconhecimento de formas e aumentar a duração de uma experiência perceptiva, por exemplo, são estratégias a partir das quais a desfamiliarização se torna “[....] o termo neoformalista geralmente aceito para designar o propósito básico da arte em nossas vidas." (THOMPSON, 1988, p. 11, tradução nossa $)^{10}$.

Já esquemas são "práticas bem padronizadas, rotinas estilísticas" (BORDWELL, 2008, p. 25) que cineastas desenvolvem como forma de solucionar problemas de encenação. Importante apontar que tais rotinas podem ser originais ou podem ser resgatadas do passado e reutilizadas no presente com base na tradição estilística do cinema. De certa maneira, é por causa de uma constante necessidade de resolver problemas que diretores passam a adotar nuances formais que perpassam as quatro funções descritas no capítulo anterior. Por fim, utilizamos o conceito de repetição, que deve ser compreendido sempre em conjunto com a ideia de variação.

Repetição e variação são dois lados de uma mesma moeda. Notar um é ficar atento ao outro. Ao pensar sobre filmes, precisamos procurar por similaridades e diferenças. Indo de umas às outras, podemos apontar motifs e contrastar as mudanças pelas quais passam, reconhecendo

\footnotetext{
${ }^{8}$ No original: the basic assumptions can be used to construct a method specific to the problems raised by each film.

${ }^{9} 0$ termo original, segundo Sher (1991), é ostraniene, que vem do russo e pode ser traduzido também como enstrangement e making it strange. Optamos pelo termo desfamiliarização tanto por sua relação com o trabalho de Thompson (1988) quanto por acreditarmos que ele expressa a essência do que Shklovsky (1991) propôs.

10 No original: Defamiliarization, then, is the general neoformalist term for the basic purpose of art in our lives.
} 
paralelismos como repetição e, ainda assim, notando variações cruciais. (BORDWELL; THOMPSON; SMITH, 2017, p. 67, tradução nossa) ${ }^{11}$.

Dessa forma, a indicação de padrões em um filme aponta para intenções específicas de uma cineasta, assim como o surgimento de uma variação (que podemos encarar como a desfamiliarização de uma rotina estabelecida) tende a surpreender o público e instigá-lo a procurar sua função no âmbito geral da obra.

Realizamos o estudo do longa-metragem Sangue negro (2007), portanto, através de um método criado com base naquilo que desejamos investigar na obra. Nele, há um elo entre: (1) análise fílmica de abordagem neoformalista (voltada ao filme em si); (2) busca por momentos nos quais a desfamiliarização da mise en scène (corpos se deslocando pelo espaço) atua como principal efeito do filme; (3) esquemas, que encaramos como soluções para problemas de encenação; e (4) repetições e variações que denotem, expressem simbolizem ou decorem elementos narrativos e formais no filme. Feita a decomposição da obra, passamos a segmentar a coleta de acordo com o objetivo do trabalho.

\section{Velar e desvelar em Sangue negro: análise da coleta de dados}

Ao decompormos Sangue negro (2007), um aspecto chamou bastante atenção. Em diversos momentos, Anderson investe numa encenação que valoriza mais o movimento dos atores pelo quadro do que aspectos de montagem rotineiramente utilizados hoje em dia como o esquema de plano/contraplano que se tornou padrão para diálogos e raccords de olhar $^{12}$. Tratam-se de movimentos que, por vezes, não apenas cumprem a função denotativa do estilo; eles também transitam pelas funções expressivas, simbólicas e decorativas, culminando num jogo de velar e desvelar corpos, rostos e objetos que se mantém recorrente na obra. Por isso, decidimos fazer um recorte da amostragem a partir do qual consideramos apenas cenas nas quais o deslocamento de atores dentro do quadro contribui para a já citada dinâmica de velar e desvelar.

Ainda sobre a inquietação que tivemos, ao que tudo indica, Anderson, em Sangue negro (2007), nega aspectos tradicionais da montagem como forma de estabelecer aquilo que Bordwell (2008) trata como gradações de ênfase na imagem. Com isso, queremos dizer que o cineasta procura conduzir nossa atenção menos a partir dos artifícios da montagem do

\footnotetext{
${ }^{11}$ No original: Repetition and variation are two sides of the same coin. To notice one is to be alert to the other. In thinking about films, we ought to look for similarities and differences. Shuttling between the two, we can point out motifs and contrast the changes they undergo, recognize parallelisms as repetition, and still spot crucial variations.

${ }^{12}$ Conceito próprio dos estudos de montagem que, segundo Bordwell, Thompson e Smith (2017) indica, basicamente, uma continuidade de movimento (ou seja, temporal) de um plano para outro. Neste caso, uma continuidade baseada na linha de olhar adotada por uma personagem.
} 
que por meio de elementos da mise en scène, sendo auxiliado por processos mentais que permitem aos espectadores serem seduzidos pela frontalidade de um rosto, pelo fugaz movimento de uma mão ou pelo som inerente a alguns dos ambientes da obra. Nasce daí a importância dos estudos de Thompson (1988) sobre os níveis de processos mentais que fazem parte da experiência fílmica. Para Thompson (1988), existem quatro destes níveis, que atuam no sistema cognitivo de uma pessoa enquanto ela vê um filme: o fisiológico, o pré-consciente, o consciente e o inconsciente. Destes quatro, apenas os três primeiros têm algum interesse para a análise fílmica neoformalista ${ }^{13}$.

Em relação ao fisiológico, tratam-se de processos que envolvem "respostas automáticas do corpo" (THOMPSON, 1988, p. 26, tradução nossa) ${ }^{14}$. A partir dele, percebemos, por exemplo, o movimento que surge depois que uma série de imagens estáticas (fotogramas) é apresentada aos nossos olhos, uma após a outra, numa velocidade considerável. São, portanto, reações sobre as quais não temos controle algum, e que auxiliam também na percepção de cores e ondas sonoras.

Já no segundo nível, pré-consciente, notamos elementos da forma fílmica sem, com isso, pensar sobre eles. Tratam-se de esquemas familiarizados ao longo do tempo, desde o surgimento do cinema. De tão acostumados que estamos com cortes, por exemplo, não nos preocupamos com eles durante um filme - a não ser que haja um processo de desfamiliarização deste aspecto.

No terceiro, temos a consciência. A partir dela, diversas habilidades cognitivas se unem como forma de buscar sentido em determinados aspectos de um filme. No que diz respeito à análise neoformalista, “[...] processos conscientes são geralmente os mais importantes, tendo em vista que obras de arte tendem a desafiar nossos modos habituais de nos relacionarmos com o mundo." (THOMPSON, 1988, p. 27, tradução nossa) ${ }^{15}$. Levando isso em consideração, decidimos segmentar a coleta em três grupos base: um voltado à mise en scène como condutora do olhar de quem assiste; outro interessado pela sua capacidade de comunicar sentimentos; e um último interessado pelas relações de poder estabelecidas durante o filme.

\footnotetext{
${ }^{13}$ Thompson (1988) aponta que um dos motivos do desinteresse neoformalista pelo nível inconsciente vem do fato de que os estudos psicanalíticos no cinema tendem a não levar em conta a experiência adquirida pelo público com outras obras de arte e com contextos históricos. Assim, há uma adaptação forçada do filme às teorias freudianas e lacanianas, a partir das quais o espectador se torna “[...] um receptor passivo de estruturas textuais [...]” (THOMPSON, 1988, p. 28, tradução nossa). Cabe ressaltar, contudo, que Thompson (1988) não condena como um todo o uso de teorias do inconsciente na análise de filmes, questionando apenas seu uso excessivo e constante, aquele que desconsidera as características particulares de cada filme.

14 No original: Physiological processes involve those automatic responses that viewers do not control.

15 No original: conscious processes are usually the most important ones, since it is here that the artwork can challenge most strongly our habitual ways of coping with the world.
} 


\subsection{Corpos que conduzem olhares}

Paul (Paul Dano), irmão de Eli (Paul Dano) chega de surpresa no escritório de Daniel com uma proposta: caso receba a quantia de quinhentos dólares, ele irá revelar o endereço do rancho de sua família, debaixo do qual há um oceano de petróleo. Após a cena em questão, que culmina no óbvio interesse de Plainview pelo que Paul tem a dizer, Anderson corta para uma outra cena na qual Daniel, Fletcher (Ciarán Hinds), Paul e H.W. são vistos diante de uma mesa, sobre a qual há um mapa aberto (Figura 1). No início, Paul apenas aponta com o indicador direito a exata faixa de terra em que a casa de sua família está, enquanto Daniel e Fletcher, atentos, procuram ouvir as indicações e H. W. se debruça sobre o pedaço de papel. A frontalidade de todos os personagens não indica nenhuma condução da mise en scène, ao passo que a simetria da composição - com dois pontos de luz dando pesos equivalentes à imagem - evoca uma relativa atmosfera de harmonia em grupo. Além disso, a moldura ao fundo sugere uma posição de destaque para Fletcher, reforçada por luzes que contornam ambos os lados de seu rosto.

Figura 1 - Paul se reúne com Daniel, Fletcher e H. W.
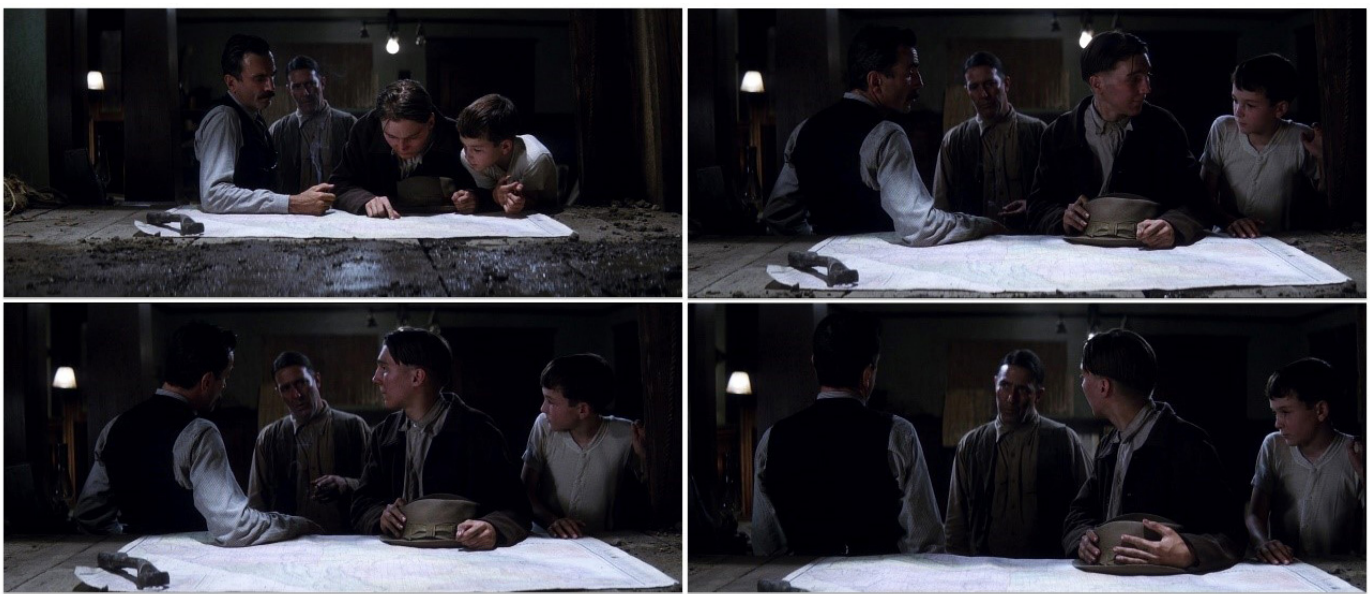

Fonte: Sangue Negro (2007), adaptado pelos autores.

Segundo Bordwell, Thompson e Smith (2017), um diretor pode "[...] alcançar um efeito poderoso ao negar a frontalidade, mantendo o público em suspense ao esconder o que o rosto de um personagem revela." (BORDWELL; THOMPSON; SMITH, 2017, p. 154, tradução nossa ${ }^{16}$. Na cena em questão, é justamente a partir dessa ideia que Anderson começa a negar a frontalidade a Daniel no momento em que Paul começa a dar cada vez mais pistas sobre a real existência de petróleo em suas terras. No entanto, a função de um corpo que dá

\footnotetext{
${ }^{16}$ No original: The director can also achieve a strong effect by denying frontality, keeping us in suspense about what a character's face reveals.
} 
as costas à câmera (Figura 1), num primeiro momento, não é criar suspense: Daniel se vira para que deixemos de nos ater ao rosto dele e passemos a olhar para as reações de Fletcher e de H. W., que interagem logo em seguida com o visitante. Nossos olhos saltam de um lado a outro, portanto. Anderson continua conduzindo nossa atenção sem precisar da montagem ${ }^{17}$.

O suspense em si surge apenas no instante em que Fletcher pergunta a Paul se alguém da família do rapaz sabe que há petróleo debaixo do rancho. A atenção do público é direcionada para o rosto de Fletcher, sobretudo porque os outros personagens negam frontalidade à câmera. Mas não é apenas isso: ao manter H.W. diante de um segundo plano banhado em sombras, a cabeça de Paul velando uma das lâmpadas que antes equilibravam a imagem e a já citada moldura que encaixota a cabeça do personagem de Fletcher, Anderson drena interesse de pontos da imagem que não contribuem com a narrativa naquele instante, permitindo que notemos com mais facilidade a troca de olhares mantida entre patrão e empregado. Por conta dos olhos de Fletcher, da capacidade que temos de encontrálos no exato instante em que devemos encontrá-los, compreendemos a dinâmica de negociação estabelecida por Plainview e a dificuldade que ambos têm de acreditar em tamanha sorte.

Figura 2 - Daniel conclui acordo com Paul
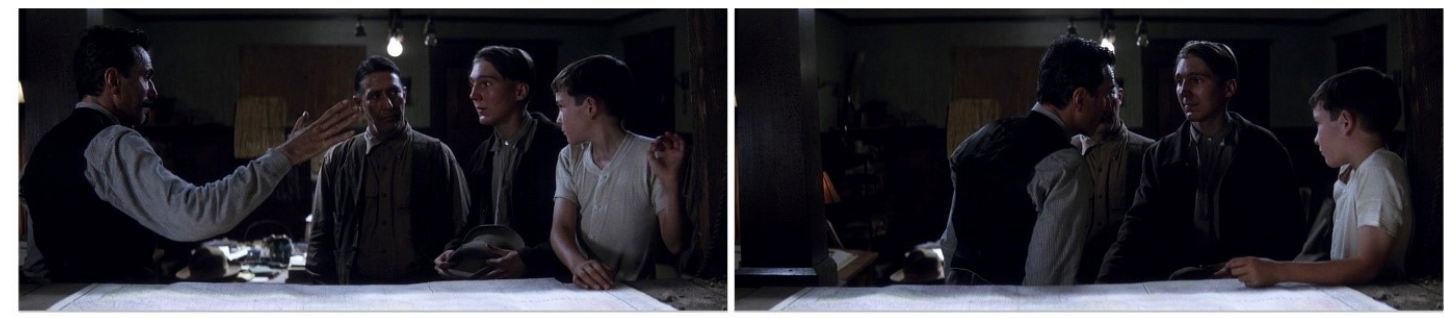

Fonte: Sangue Negro (2007), adaptado pelos autores.

No encerramento da cena, há mais algum esforço para conduzir olhares a partir de corpos velados e desvelados no espaço. Daniel ergue a mão na direção de Paul, prestes a fechar o acordo (Figura 2). Assim que Paul atende ao pedido, Daniel avança, velando o rosto de Fletcher - que antes chamava muita atenção por conta das luzes e da moldura - e diz ao novo sócio que, caso aquilo que ouviu seja mentira, viajará para pegar "mais do que o dinheiro de volta" (SANGUE..., 2007, doc. não paginado) . Trata-se, portanto, de uma ameaça. Assim, faz sentido que Anderson se utilize mais uma vez do jogo de velar e desvelar que indicamos para destacar o rosto de Paul. Aflito, o garoto se coloca no terço superior direito

\footnotetext{
${ }^{17}$ Há teorias que apontam esse tipo de encenação como sendo uma espécie de montagem dentro do quadro que depende do público para acontecer - o movimento dos olhos de quem assiste, segundo os adeptos dessa visão, executaria os cortes necessários. Para fins de estudo, tratamos, no entanto, da concepção clássica, que aponta para o encadeamento de planos como elemento-base da montagem, e a atenção do público como sendo guiada pelos cineastas.
} 
da imagem, ponto de forte interesse visual, e, assim, demonstra o alto nível de controle que o diretor mantém sobre sua composição.

Ao falarmos sobre condução do olhar, frontalidade, movimento de corpos e também sobre terços da imagem, nos ativemos à função denotativa do estilo. Porém, a cena também cria certa dose de suspense e de medo, comunicando tais afetos e sensações ao público com o auxílio do mesmo jogo de velar e desvelar citado anteriormente. A forma fílmica proposta por Anderson, portanto, também aposta na função expressiva dos estudos estilísticos, fazendo dela, inclusive, a mais importante para que experienciemos a trajetória de Daniel Plainview em sua totalidade.

\subsection{Corpos que estabelecem relações de poder}

Um dos motifs de Sangue negro (2007) diz respeito ao método que Daniel Plainview adota para falar com as famílias que moram em terrenos de seu interesse. De voz sempre calma e trejeitos elegantes, o personagem parece sempre à vontade diante delas, mas basta um momento de silêncio para que o ódio que nutre pelas pessoas transborde de seu rosto e de seus gestos.

Este ato de transbordar algum nível de desprezo que fora reprimido durante uma conversa dá a entender que Plainview trata o contato interpessoal como uma espécie de tortura auto imposta. Não à toa, ele diz a Henry (John O'Connor), durante uma conversa regada a bebidas, que o motivo pelo qual quer ganhar muito dinheiro é "para poder fugir de toda essa gente" (SANGUE..., 2007, doc. não paginado). Mas como Anderson se utiliza da mise en scène para retratar esse conflito interno tão marcante? 0 deslocamento de atores pelo quadro em Sangue negro (2007), além de conduzir a atenção do público, teria como outra de suas funções reforçar nuances do tipo?

Ambos os questionamentos dizem respeito à função denotativa aliada à função simbólica do estilo. É preciso, para atender a essa necessidade do personagem, que aquilo que vejamos simbolize conceitos mais abstratos da personalidade de Plainview. Durante a coleta, encontramos, como exemplo disso, o momento no qual a primeira plataforma de Little Boston é inaugurada. Nele, todas as famílias estão presentes, assim como a congregação de Eli, os pequenos H.W. e Mary Sunday (Sydney McCallister) e os funcionários de Daniel.

Por consolidar o conflito entre os personagens de Day-Lewis e Dano, central em Sangue negro (2007), trata-se de uma sequência importante do roteiro escrita pelo próprio Anderson. Nela, Eli aguarda para que tenha a chance de dar sua benção à plataforma 
Sobre corpos isolados na imagem: a mise em scène em Sangue negro, de Paul Thomas Anderson

construída por Plainview, o que representaria não apenas uma satisfação típica de sua função como referência religiosa, mas também uma maneira de demarcar território diante de seu algoz - e também diante das pessoas que moram no local, tendo em vista que são elas que sustentam sua congregação.

Plainview, da mesma forma, encara o início dos trabalhos de perfuração como o instante em que pode se apresentar como um líder, alguém que cumpriu parte do que fora prometido no dia em que encontrou aquelas pessoas pela primeira vez e que estaria disposto a mudar a vida de todos para melhor, ainda que isso não passe de uma mentira. Além disso, o personagem vê no evento uma oportunidade de impedir que Eli continue sendo a principal referência de Little Boston, motivado, sobretudo, pelo desinteresse que nutre por crenças ou qualquer tipo de doutrina. Anderson cria, portanto, uma espécie de duelo travado entre aquele que empunha o capital e aquele que manuseia os escritos sagrados.

Figura 3 - Daniel e Eli aguardam o início da perfuração

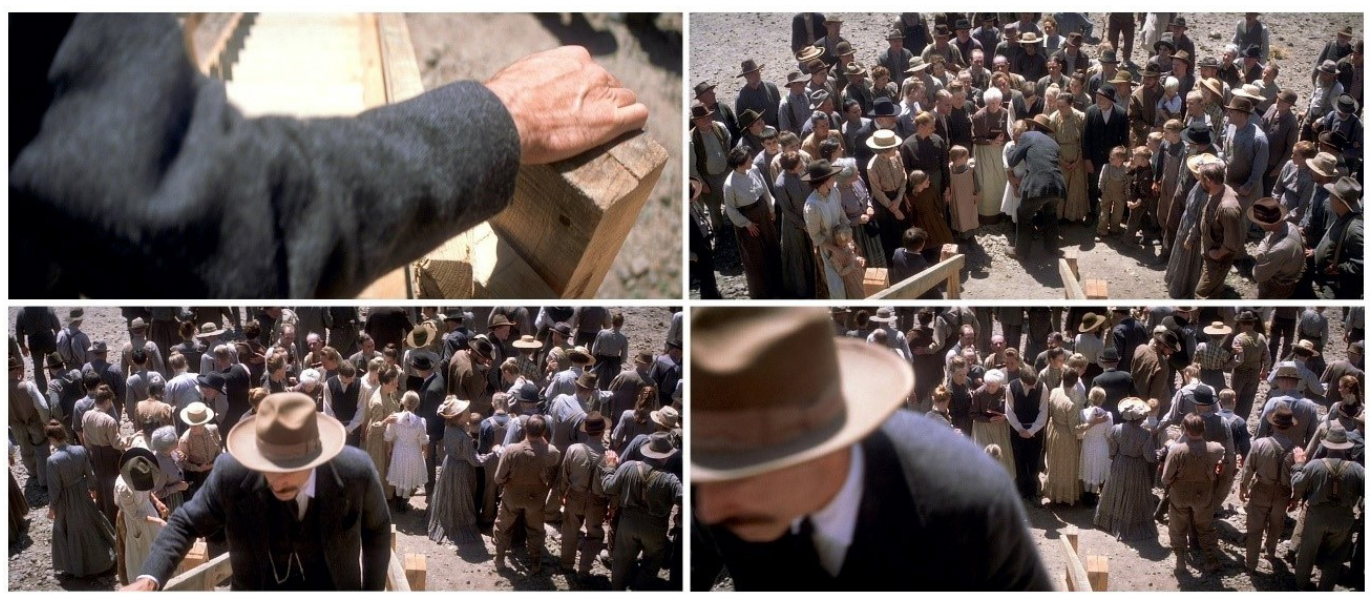

Fonte: Sangue Negro (2007), adaptado pelos autores.

Tendo em mente que "Para cineastas que trabalham com narrativas, o posicionamento da câmera é central para narrar visualmente uma história." (BORDWELL; THOMPSON; SMITH, 2017, p. 191, tradução nossa) ${ }^{18}$, chama atenção a forma com que Daniel entra no quadro momentos antes de descer as escadas para falar com as famílias (Figura 3). Por meio do posicionamento de sua câmera e de uma lente de curta distância focal, capaz de manter o foco ao longo de todos os planos da tomada, Anderson exagera a perspectiva da imagem e faz com que o braço do personagem tome conta de todo o quadro. Em seguida, acompanhamos o momento em que ele desce as escadas e, por conta novamente da perspectiva, diminui de tamanho na tela. "Pequeno", ele dá um abraço em Mary e ignora a

\footnotetext{
${ }^{18}$ No original: For filmmakers working with narrative form, camera placement is central to visual storytelling.
} 
turma de Eli, que aguarda o momento em que poderá realizar a benção solicitada ao empresário dias antes. Não demora muito para que Plainview retorne ao seu posto e, assim, cresça outra vez na imagem, tomando para si um espaço pictórico que, em tese, deveria ser dos corpos que ele vela degraus acima.

Consideramos que o exagero da perspectiva, a posição da câmera e a performance dos atores, sejam eles principais ou coadjuvantes, atendem às exigências da função denotativa. No plano simbólico, essa associação da cena com o método utilizado por Daniel nos encontros com as famílias sugere a ideia de que ele se vê num patamar (Moral? Financeiro?) muito superior do que aquele que julga ser o das pessoas de Little Boston (ou de qualquer outro lugar). Portanto, o posicionamento da câmera de Anderson, somado à movimentação do corpo de Plainview pelo quadro simboliza esse eterno retorno do personagem à sua condição de isolamento auto imposto e de superioridade narcisista, traduzidos a partir de recursos próprios do design fílmico.

\subsection{Corpos que comunicam afetos}

$\mathrm{Na}$ dimensão expressiva do estilo cinematográfico, encontramos o principal interesse de Paul Thomas Anderson ao definir a forma de Sangue negro (2017): fazer visível aquilo que se passa no interior de seu protagonista. É com base no atrito provocado entre a vontade que Daniel tem de se livrar das pessoas e a necessidade que ele tem de se aproximar delas que o diretor concebe seu filme.

Figura 4 - Daniel reage à morte de Joe Gundha

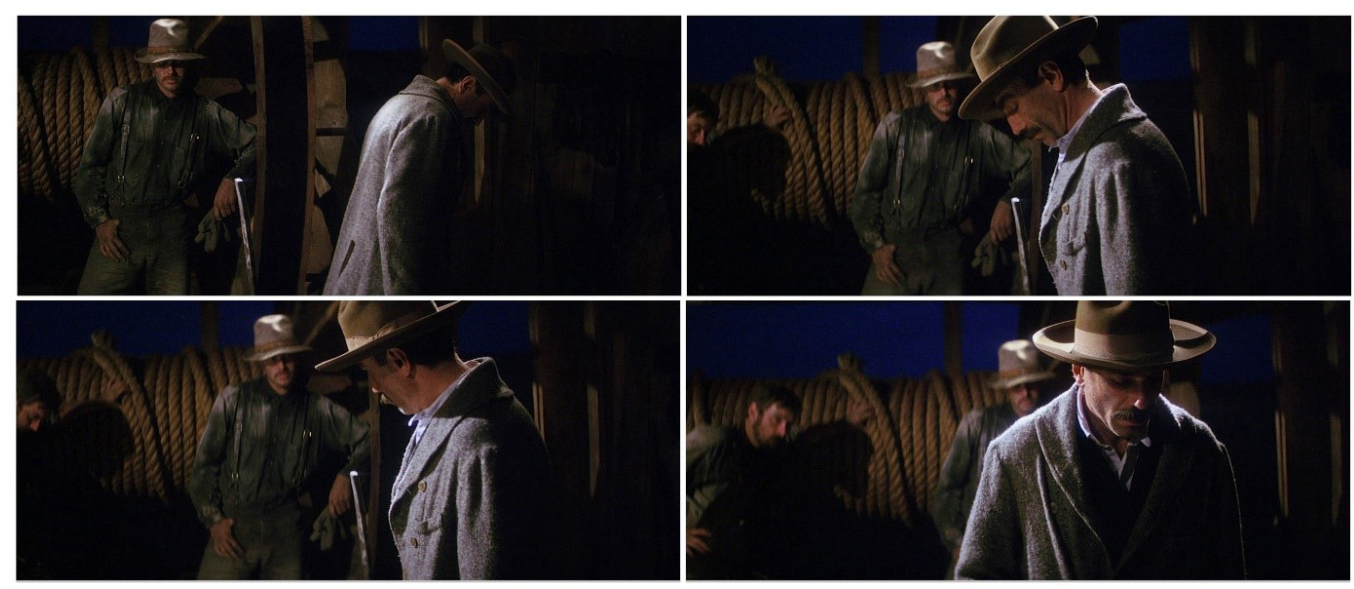

Fonte: Sangue Negro (2007), adaptado pelos autores.

Falamos de afetos comunicados pela forma fílmica. Assim, na coleta realizada, optamos pela cena posterior ao momento em que Plainview fica sabendo sobre a morte de 
Joe Gundha (não creditado). Gundha, até o flashback que anuncia sua morte, jamais é visto no filme. Por conta disso, chama atenção como Daniel reage ao olhar para o corpo do personagem estendido no chão, na parte central da plataforma (Figura 4). De início, destacase o contraste entre as posturas do protagonista, sugerindo retraimento, dor, e a de um funcionário que se encontra na metade esquerda do quadro, para o qual a morte de Gundha parece não significar mais do que uma possível repreensão de seu chefe. Além da disposição dos corpos, o jogo de velar e desvelar continua presente através das sombras que cobrem a parte frontal de Daniel, escondendo seu rosto no momento exato em que ele fecha os olhos.

Segundo Bordwell, Thompson e Smith (2017), ao investigarmos quais são as funções de elementos específicos num filme, é comum que nos perguntemos como esses elementos chegaram ali. No entanto, os autores indicam ser melhor para analistas que essa pergunta seja refeita: ao invés de questionarmos o como, é preciso que perguntemos o que esse elemento faz no momento em que ele aparece. Desse modo, para entender a função do deslocamento e da expressão corporal de Plainview ao observar o corpo de Gundha, recorremos novamente à forma fílmica, mais precisamente ao conceito de repetição. Ora, se temos na figura 4 um raro momento íntimo de Plainview revelado pela imagem, partimos do pressuposto de que isso sugere que a dinâmica de velar e desvelar sobre a qual falamos ao longo do artigo também diz respeito à subjetividade do personagem. Uma indicação disso pode ser encontrada na maneira através da qual Anderson conduz a mise en scène em dois instantes específicos: a morte de H. B. Ailman (Barry Del Sherman) durante trabalho numa das primeiras perfurações de Plainview e o acidente que tira a vida do próprio Gundha (Figura 5).

Figura 5 - Ailman e Gundha morrem; Plainview e Ailman trabalham juntos
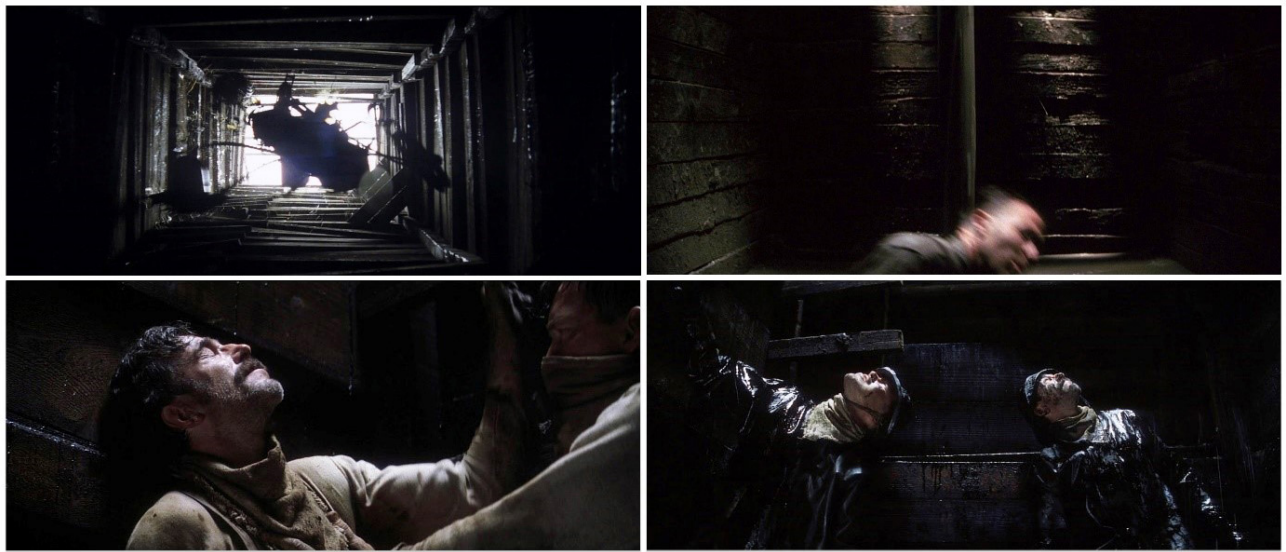

Fonte: Sangue Negro (2007), adaptado pelos autores. 
Colocadas lado a lado, as mortes de Gundha e Ailman sugerem uma continuidade a partir das semelhanças formais e narrativas que apresentam. Em ambos os casos, um objeto despenca por acidente e atinge os personagens, matando-os instantaneamente.

Intrigados por essa semelhança, notamos a necessidade de observar com mais atenção como Plainview e Ailman se relacionam no início do filme. Nesse sentido, dois momentos se destacam: ao passar mal dentro de um dos poços de drenagem, Plainview recebe o auxílio de Ailman, demonstrando gratidão ao rapaz logo em seguida; em outro instante, ambos se tornam pesos idênticos na imagem, compartilhando uma harmonia visual que, no entanto, não se limita a essa cena, mantendo-se constante sempre que estão juntos.

O que nos leva, outra vez, à figura 4. Se Ailman e Daniel Plainview eram tão próximos como a mise en scène do filme sugere, a morte de Gundha, por lembrar tanto a do seu antigo amigo e colega de trabalho, pode ser encarada como um gatilho afetivo que revela nuances de sua personalidade. Assim como acontece com o público mais atento, Daniel se lembra do acidente de Ailman ao ver o corpo de Gundha tombado à sua frente. Não interessa para ele quem Gundha é, portanto - e Fletcher reforça isso ao afirmar, numa cena anterior, que os dois não se conheciam. 0 que conta é a proximidade visual mantida entre memória e morte.

Sabendo da relação que manteve com Ailman e de como a morte de Gundha faz Plainview se lembrar do amigo, notamos que a cena trata de desvelar outras camadas afetivas do personagem, diretamente ligadas ao trauma de seu passado. Depois de observar por alguns segundos o corpo do funcionário, Daniel se vira para o lado oposto, mantendo-se de olhos fechados e, com isso, reforçando ainda mais o choque sentido. Em seguida, ele olha para o colega parado à sua direita e, percebendo que é observado, desvia o olhar imediatamente, dando as costas para o rapaz. Com base em reações semelhantes ${ }^{19}$ vistas ao longo do filme, podemos tratar a atitude de Daniel como o momento em que assume sua maneira de lidar com o mundo. É escondendo das pessoas à sua volta tudo que possa dar acesso ao que ele sente que Plainview lida com elas. Trata-se, então, do mesmo jogo de velar e desvelar que analisamos até aqui, mas adaptado à dimensão afetiva do personagem e traduzido por elementos próprios da mise en scène no cinema.

\section{Considerações Finais}

De certa forma, Sangue negro (2007) pode ser encarado como um filme que sintetiza o estranhamento provocado pela obra de Anderson como um todo. Plainview também é um sujeito movido a desejos difíces de traduzir em palavras e também está à deriva em uma

\footnotetext{
${ }^{19} \mathrm{O}$ início do batismo e o instante no qual Plainview observa Eli partindo de Little Boston se destacam.
} 
busca que, a princípio, apenas ele parece entender. No desenrolar narrativo e estilístico do filme, vão sendo reveladas nuances afetivas que, se não todas, ao menos trazem algumas respostas sobre o seu passado e a influência dele sobre a maneira com que o personagem se porta diante de outras pessoas.

Anderson, através de um uso sutil do efeito de desfamiliarização, alcançado através de atributos da mise en scène que sempre cumprem funções importantes para a narrativa, vai na contramão do que é comum na produção contemporânea de seu país ao permitir que os atores, dirigidos, sejam os responsáveis pela condução do interesse na imagem. Negando cortes na maioria dos exemplos coletados, priorizando o velar e desvelar de informações na imagem e intensificando sentimentos a partir da desaceleração do ritmo, o diretor cria uma experiência que se apoia, principalmente, na função expressiva do estilo cinematográfico para dar forma ao que não se vê, ou seja, para comunicar a dimensão do sensível e fazer dela o principal tema de seu filme.

Outros estudos do tipo, no entanto, precisam ser realizados para que tratemos as escolhas de Anderson em Sangue negro (2007) como um padrão em sua carreira. É com esse pensamento que seguimos na busca por uma compreensão cada vez mais ampla dos procedimentos através dos quais ele faz da técnica e da expressividade o coração de seu cinema.

\section{Financiamento}

O presente trabalho foi realizado com apoio da Coordenação de Aperfeiçoamento de Pessoal de Nível Superior - Brasil (CAPES).

\section{Referências}

AUMONT, Jacques. 0 cinema e a encenação. Lisboa: Texto \& Grafia, 2006.

BAECQUE, Antoine de. Cinefilia. São Paulo: Cosac Naify, 2010.

BORDWELL, David. Figuras traçadas na luz: a encenação no cinema. São Paulo: Papirus, 2008.

BORDWELL, David; THOMPSON, Kristin; SMITH, Jeff. Film art: an introduction. 11th. ed. Wisconsin: University of Wisconsin, 2017.

BORDWELL, David. Sobre a história do estilo cinematográfico. São Paulo: Unicamp, 2013. 
CARO, Mark. Abundance of symbols in 'Magnolia' has filmgoers looking for clues. Chicago Tribune, Chicago, 23 Jan. 2000. Disponível em: https://www.chicagotribune.com/news/ctxpm-2000-01-23-0001230275-story.html. Acesso em: 9 dez. 2018

IMDB. Paul Thomas Anderson. [S. l.], [2018a]. Disponível em: https://www.imdb.com/name/nm0000759/?ref_=tt_ov_dr. Acesso em: 25 out. 2018.

IMDB. Paul Thomas Anderson: awards. [S. l.], [2018b]. Disponível em: https://www.imdb.com/name/nm0000759/awards. Acesso em: 10 dez. 2018.

KING, Geoff. Independent American Cinema. Indiana: Indiana University Press, 2005.

OLIVEIRA JÚNIOR, Luiz Carlos. A mise en scène no cinema: do clássico ao cinema de fluxo. São Paulo: Papirus, 2013.

SANGUE negro. Direção: Paul Thomas Anderson. Produção: Paul Thomas Anderson, Daniel Lupi e Joanne Sellar. Roteiro: Paul Thomas Anderson. Los Angeles: Paramount Vantage, 2007. 1 disco blu-ray (158 min), son., color.

SHER, Benjamin. Shklovsky and the revolution. In: SHKLOVSKY, Viktor. Theory of prose. 2nd. ed. Illinois: Dalkey Archive Press, 1991. Introdução, p. 15-21.

SHKLOVSKY, Victor. Art as technique. In: Russian Formalist Criticism: Four Essays. 2. ed. Nebrasca: University of Nebraska Press, 2012.

SHKLOVSKY, Victor. Theory of prose. 2 nd. ed. Illinois: Dalkey Archive Press, 1991.

TAFOYA, Scout. NYFF 2014: Paul Thomas Anderson's "inherent vice". [S. l.]: Festivals and Awards, 5 Oct. 2014. Disponível em: https://www.rogerebert.com/festivals-andawards/nyff-2014-paul-thomas-andersons-inherent-vice. Acesso em: 9 dez. 2018.

THOMPSON, Kristin. Breaking the glass armor: neoformalist film analysis. Princeton: Princeton University Press, 1988.

TOLES, George. Paul Thomas Anderson. Urbana: University of Illinois Press, 2016.

WÖLFFLIN, Heinrich. Renascença e Barroco: estudo sobre a essência do estilo barroco e a sua origem na Itália. 2. ed. São Paulo: Perspectiva, 2012.

On Isolated Bodies in the Image: The Mise en scène in There Will Be Blood (2007), By Paul Thomas Anderson

\footnotetext{
Abstract

The article aims to investigate elements of mise en scène present in There will be blood (2007), directed by Paul Thomas Anderson, associating them with the functions of film style described by Bordwell (2008). From a qualitative approach and
} 
using film analysis as a method, the research was based on three moments of the movie, chosen from our interest in studying how Anderson leads the positioning and movement of actors within the frame. As a result, we observe that the filmmaker, based on a constant interest in the minimum aspects of the twodimensional image, bets on a recurring game of watching and unveiling in which not only bodies and faces are concealed and assumed but also important subjective representations that act towards a better understanding of the narrative.

\section{Keywords}

Cinema. Mise en scène. There Will Be Blood. Film Style. Paul Thomas Anderson.

Recebido em 28/04/2019

Aceito em 19/08/2019 